\title{
DESPRE SUFIXUL VERBAL -Ui ÎN GRAIURILE DACOROMÂNE SUDICE
}

\author{
MARIA MARIN
}

1. În lucrările de dialectologie se întâlnesc puține observații asupra particularităților zonale privitoare la formarea cuvintelor. Astfel, în TDR, descrierea unităților dialectale ale dacoromânei cuprinde câteva remarci referitoare la subdialectul muntean, între care şi derivarea cu sufixe (Ionică 1984: 187-190), unde nu se vorbeşte însă de sufixe verbale; o serie de observaţii asupra utilizării şi a frecvenței sufixelor diminutivale sunt prezentate în descrierea subdialectului maramureșean (Vulpe 1984: 345-346); de altfel, graiurile maramureşene reținuseră atenția anterior din acest punct de vedere, un studiu amplu asupra acestui aspect fiind semnat de Ion Faiciuc (Faiciuc 1972); mai recent, subiectul a fost abordat în volumul destinat graiurilor din Sălaj (TD-Sălaj); pe baza materialului înregistrat din şase localități, Carmen-Ioana Radu realizează o desriere pertinentă asupra chestiunii (Radu 2017).

Amplul studiu consacrat sufixului -ui, semnat de Laura Vasiliu (L. Vasiliu 1967), este cea mai cuprinzătoare şi documentată descriere a particularităţilor utilizării acestuia în limba română standard, cu o serie de observații judicioase privind varianta populară a limbii române, dar, în afară de indicația regional (reg.) însoțind anumite cuvinte, alte referiri propriu-zise la aspecte dialectale lipsesc.

2. În ceea ce priveşte proveniența sufixului verbal -ui, reținem că acesta este de origine slavă (desprins din verbe în -ovati, cu prezentul în -ujo, ca dărui < bulg. darovam, obştuí < bulg. otštiuvam, şăguí < bulg. šaguvam se, cu mențiunea că el apare, între altele, şi la verbe de origine maghiară pătrunse în română prin intermediar slav (de ex. aldui $<$ vsl. alduvam $<$ magh. áldani, bănui $<$ vsl. banuvam $<$ magh. banni (L. Vasiliu 1967: 113).

Sextil Puşcariu admite că verbele în -ui sunt împrumutate din maghiară prin mijlocire slavă într-o perioadă în care românii n-aveau contact direct cu maghiarii, însă nu acceptă ideea bilingvismului românilor cu slavii, aşa cum sugerase anterior Skok 1929: 776-790; 1936-1938: 214-215), argumentând că slavii erau ei bilingvi (Puşcariu 1929-1930: 520-521) ${ }^{1}$.

\footnotetext{
${ }^{1}$ Observații interesante în legătură cu aportul elementelor de origine maghiară în consolidarea sufixului -ui în română se găsesc şi în Petrovici 1948: 188-189, precum şi în Rosetti 1950: 88-99.

FD, XXXVIII, Bucureşti, 2019, p. 57-66
} 
De subliniat remarca Laurei Vasiliu care susține că „sufixul a fost detaşat de la verbele împrumutate analizabile [s.n., M. M.] pentru români: dărui < vsl. darovati, față de dar sau milui < vsl. milovati, față de milă (L. Vasiliu, loc. cit.).

Reținem, de asemenea, că în textele româneşti vechi derivatele verbale în -ui sunt reduse ca număr; dintre cele semnalate amintim doar pe îngădui, ,a consimți, a accepta", atestat în Cazania lui Coresi (Densusianu, HLR, II: 349) şi păstrat până astzi în limba română.

3. Observațiile care urmează au la bază Dicționarul graiurilor dacoromâne sudice (DGS) ${ }^{2}$ şi, în consecință, fiind vorba de un dicționar d i a 1 e c t a l, materialul ilustrează e x c l u s i v elemente lexicale dialectale (cuvinte, forme, sensuri) considerate ca atare în dicționarele limbii române (DLR, DM, DEX) sau neatestate până la apariţia acestuia.

La o inventariere a verbelor (cuvinte-titlu şi variante) prezente în DGS am constatat că numărul total al acestora este de 3347 (Marin 2019: 263), dintre care, spre deosebire de româna standard, ponderea cea mai mare o au verbele de conjugarea a IV-a, numărând 2092 de unități, ceea ce reprezintă un procent de $62,49 \%$, adică aproape dublu față de cele de conjugarea I, cu un procent de abia $32,27 \%)^{3}$.

4. În vorbirea popular-dialectală una dintre sursele de îmbogățire a inventarului verbelor de conjugarea a IV-a o reprezintă cele în -ui, categorie foarte numeroasă şi productivă, înregistrând 310 unități, adică $14,43 \%$ din totalul verbelor aparținând clasei cu terminația în $-i,-\imath^{4}$.

Aşa după cum s-a subliniat deja, ,odată constituit, sufixul a fost detaşat de la verbele împrumutate în diversele faze ale limbii [...] şi ca element de derivare a verbelor, mai ales, de la substantive (fáptă > făptuí, preț> prețuí (L. Vasiliu 1967: 114), dar şi de la alte părți de vorbire.

4.1. Cele mai multe derivate verbale în -ui provin de la nume (în special substantive şi, mai rar, adjective sau numerale). Categoria nominalelor numără 194 de unităti ceea ce înseamnă $62,91 \%$ din totalul verbelor în $-u i^{5}$ : cremui ,a da cu cremă pe încălțăminte" < crémă, mucuí [d. nas] „,a curge (când omul e răcit)" <

${ }^{2}$ Constatările noastre se referă exclusiv la aria sudică, întrucât nu beneficiem de lucrări similare pentru celelalte zone sau subdialecte ale dacoromânei (cf. Marin 2019: 263).

${ }^{3}$ Statistica privind ,dinamica claselor verbale în româna actuală", realizată de profesorul Gr. Brâncuş (Brâncuş 2008 [1976]: 12-13) pe baza materialului din Dicționarul explicativ al limbii române (DEX, Bucureşti, 1975), evidențiază preponderența numerică a verbelor de conjugarea I în româna actuală, unde „tipul I de conjugare se caracterizează printr-o foarte mare productivitate”, verbele în - $a$ nu numai că egalează, dar şi depăşesc considerabil pe cele în $-i$.

${ }^{4}$ De observat că şi între verbele în $-i,-\hat{\imath}$ din româna standard o poziție puternică o dețin cele în -ui (GALR, I: 557).

${ }^{5}$ Şi în ceea ce priveşte limba comună s-a remarcat „preferința vădită a sufixului -ui pentru teme nominale" (L. Vasiliu 1967: 119). 
$m u c$, peciui ,a tăia carnea în p e c i i” $<$ pécie $^{6}$, prenui ,a vântura din nou murăturile, vinul" < pre + nui $(<$ noí $<$ nou $)$.

În cazul derivării de la teme nominale cu sufixul -ui, în general, la trecerea de la substantiv la verb se pierd intodeauna finala vocalică sau formată dintr-un diftong şi sufixul temei: viérme > viermui [d. fructe] „,a face viermi”, hurdắu > hurdui ,a bate laptele închegat (în h u r d ă u)", păşúne > păşuí ,,a duce la păşune; a paşte" ş.a. Foarte rar, accidental, prin această trecere se pierde şi din tema cuvântului de bază: buruí $\mathbf{1}^{\mathbf{0}}$,a curăța de buruieni; a plivi”, sens atestat în Dâmbovița, şi $\mathbf{2}^{\mathbf{0}}$,a se umple de buruieni; a se îmburuiena", întâlnit într-un text din județul Tulcea.

În cazul derivatelor nominale, dat fiind specificul dicționarului supus cercetării, este vorba, în primul rând, de substantive denumind realități, activități, obiecte caracteristice lumii rurale, cele mai multe elemente vechi în limbă ${ }^{7}$ şi considerabil mai puține neologisme. Substantivele de la care derivă verbele în -ui sunt folosite, de regulă, în formă de singular şi, mai rar, de plural: baci > băciui ,a lucra ca baci”, bârnă > bârnui „,a aşeza bârnele pentru a ridica pereții casei”, caş $>$ căşuí „a scrobi urzeala cu c a ş”, clipci s.f. pluralul substantivului clípcă „colivie” > clipciui „a bate leațuri la pereții casei de bârne, pentru a fixa tencuiala"; în schimb, forma sclipciuí, cu acelaşi sens, poate fi interpretată fie ca variantă a lui clipciuí, cu $\mathrm{cl}>\mathrm{scl}$ (cf. sclăbi, sclăbuc), fie ca derivat de la sclípce s.f. pl. „leațuri (sau nuiele) care se bat la pereții casei (pentru a se fixa tencuiala)", fáță, pl. fețe > fețui ,a lipi netezind pereții; a fățui”, frățtui ,a rupe copilii la porumb; a copili” îşi are originea, indubitabil, în frați (formă de plural pentru frate) „lăstari la porumb”, atestat în DA, s.v. fráte $4^{\circ}$; sấrmă > sârmui ,a (se) bate rețea de sârmă (cu trestie) la pereții casei", stup > stupui ,a lua fagurii (cu miere) din stup, omorând albinele".

Uneori, de la acelaşi substantiv se creează două derivate, unul de la singular şi altul de la plural: şipcă $>$ şipcui, pl. şipci $>$ şipciuí, ambele cu sensul ,a bate şipci la pereții casei”, teácă $>$ tecuí, teci $>$ teciuí, ambele cu sensul ,a dezghioca tecile de fasole" ş.a.

O serie bine reprezentată este constituită din derivate provenite de la regionalisme, de regulă, specifice ariei sudice (Oltenia, Muntenia, Dobrogea): clóţă „cloşcă” > cloțui [d. găini] ,a cloci”, dert „supărare” > dertui ,,a se întrista, a se supăra”, giur ,lemn cu o crăcană la capăt cu care se freacă urzicile fierte, se bat ouăle sau laptele prins" > giuruí ,a bate laptele prins, a freca urzicile fierte cu g i u r u l”, pârlắu $1^{\circ}$,vas mare dintr-un buştean scobit (în formă de cilindru) în care se opăresc rufele, tortul etc." > pârlui ,a (se) opări rufele în p â r l ă u", , stici, variantă a substantivului ştic ,presă, teasc” > sticiui ,,a (se) zdrobi strugurii pentru

\footnotetext{
${ }^{6}$ Cuvântul peciuí poate fi interpretat şi ca un derivat de la verbul pecí, cu schimbarea elementului derivativ.

${ }^{7}$ Este, de altfel, recunoscut faptul că ,temele la care se ataşează sufixul -ui sunt în mare majoritate vechi şi foarte vechi (L. Vasiliu 1967: 122).

${ }^{8}$ Verbul pârluí figurează în L. Vasiliu 1967: 127 între formele considerate neanalizabile.
} 
must, a (se) tescui”, țámbră „scândură folosită la construcția gardului” > țămbruí „a căptuşi cu ț a m b r e, cu scânduri galeria unei mine”, țanc „băț cu care se măsoară, însemnându-se cu câte o crestătură, cantitatea de lapte muls de la oi cu ocazia alcătuirii stânii sau cantitatea de rachiu obținută la distilarea unui cazan de borhot" > țăncuí ,a măsura un lichid cu ț a n c u l”, zmiță „lână cu firul scurt tunsă de pe miei; miță" > zmițui ,a tunde z m i ț e 1 e; a mițui".

Rareori, substantivul (termen regional) de proveniență a unui derivat nu figurează în DGS: pălgui ,,a vântura sămânța de grâu (aruncând-o în vânt cu ajutorul unui vas)] derivă, după toate probabilitățile, de la pấlgă „oală mică de o jumătate de litru", termen existent în DLR, s.v. pấlcă, provenit din zona Râmnicu Vâlcea şi preluat din Lexic reg., I: 84.

O categorie mai puțin numeroasă este reprezentată de verbe (derivate nominale) caracterizate prin anumite particularități fonetice obişnuite sau accidentale: grăui < grâuí (cu $\breve{a}<\hat{a}$ ), ,a treiera a doua oară (după ce s-au scos paiele de pe arie), pentru a separa boabele (de grâu) de spicele (rămase întregi, după treieratul cu cai)", hărcuí < ărcuí < arcuí ,,a încovoia, a curba un lemn” (cu $h$ aspirat, cf. arác > harác, arcá > harcá, arípă > harípă ş.a.) (Ionică 1984: 172) sau călcuí ,a face clacă, a presta clacă (pentru boier)" < clăcuí < clácă (cu metateza clă $>$ căl (cf. clócot $>$ cólcot, clocotí > colcotí (Ionică 1984: 173).

Datorită evoluției fonetice, s-au creat, uneori, omonime provenite de la termeni diferiți, precum lăcui ${ }^{l}$, ,a locui” (cu $o>\breve{a}$ ) şi lăcui ${ }^{2}$,, lecui” (cu $e>\breve{a}$ ) sau pălui $^{l}$,a aşeza (rufele puse la spălat) în straturi (cu cenuşă între ele)" < pálă „grămadă, strat din ceva aşezat ordonat" şi pălui ${ }^{2}$ refl. $\mathbf{1}^{\circ}$ [d. iarba cosită] ,,a se zvânta, a se usca, a se păli"; $\mathbf{2}^{\mathbf{0}}$ [d. cereale] ,a da în pârg; a se îngălbeni” sau plăsui ${ }^{l}$ „a muşuroi porumbul cu p 1 a s u l”; plăsui ${ }^{2}$,a vântura cerealele, boabele (după treierat) cu ajutorul unei $\mathrm{p} 1$ a s e".

În cazul lui dăinuí, var. s.v. dăinăi ,a legăna copilul mic (cântându-i)”, verbul pare a fi derivat din doini $<$ doinăa, trecând prin varianta doinăi $<$ dăinui, cu schimbarea sufixului concurent -ăi în -ui ( cf. L. Vasiliu 1967: 121).

În seria regionalismelor încadrăm şi verbele (derivate de la teme nominale) prefixate cu în-lîm-, considerate, pe bună dreptate, caracteristice, în special, graiurilor munteneşti (Iordan 1936: 43; Mărgărit 2009: 183 ş. urm.). Majoritatea dintre acestea sunt variante prefixate ale verbelor simple: imbârnuí < bârnuí, impârgui < pârgui, îndrăcui $<$ drăcui, înlocuí < locuí, întencui < tencuí ş.a. Există însă şi forme de acest tip derivate direct din nume (care, după informațiile noastre) nu cunosc şi forma neprefixată: înghesuí, inşirui, învălui ş.a.

Stabilirea numelui sau a elementului nominal de la care s-a creat derivatul în -ui este uneori dificilă şi nu întotdeauna soluția propusă în dicționare corespunde realității.

Burfui este atestat în DGS cu două variante şi cu trei sensuri: $\mathbf{1}^{\mathbf{0}}$,, a scotoci, a cotrobăi": [În timpul războiului, turcii] umbla şi burfuia şi vai de lume. Lua burfele, ce găsea; $\mathbf{2}^{\circ}$ refl. ,a se nărui, a se surpa”: Să nu se burfuie pământu, ca să apuce 
cetățeni jos [în puț], să-i omoare; $\mathbf{3}^{\mathbf{0}}$ var. borfăi [la treieratul cu cai] ,, a întoarce spicele pe arie, pentru a separa paiele de boabe": Şi după ce grohoia [grâul] bine, îl mai întorceam cu o lopată, aşa dă jur împrejur, îl borfăíam.

În DA, burfui apare cu un singur sens şi anume ,a face întâia praşilă a porumbului”; cuvântul este considerat sinonim cu borhăi i, iar pentru etimologie nu se face nici o propunere.

Borhăí este discutat s.v. burduhăní, care, la rândul său, este prezentat împreună cu varianta borhăni ,a sfâşia cu cruzime un animal, precum fac lupii când apucă o vacă", având şi el ca sinonim pe borhăí, verb folosit cu referire la vitele care se împung cu coarnele în burtă până se spintecă. Întreaga discuție din DA se încheie prin a declara toată suita de variante, incluzându-l şi pe burfuí, drept derivate din burduhán. Fără a ne referi la variantele de sub cuvântul burduhăní, în legătură cu care nu avem nici o obiecție, considerăm că ambele verbe, borfăí, burfuí, sunt derivate de la substantivul búrfă, pl. búrfe (cf. chiar citatul de sub sensul $1^{\circ}$ din DGS) sau boárfä, pl. boárfe.

În schimb, borfăi , discutat în DA separat şi fără nici o trimitere la burfuí, este definit $\mathbf{1}^{\mathbf{0}}$,a despoia pe cineva, luându-i boarfele de pe el”; $\mathbf{2}^{\mathbf{0}}$,a scotoci, a căuta prin boarfe, a răscoli boarfele" este considerat, pe bună dreptate, derivat din boárfe (care, se ştie, are şi varianta búrfe, v. DA s.v.).

Aşadar, în DGS, borfăi este privit ca variantă a lui burfuí, sensurile $\mathbf{2}^{\mathbf{0}}$ şi $\mathbf{3}^{\mathbf{0}}$, folosite metaforic, se apropie până la confuzie.

4.2. Următorul grup considerat după numărul de elemente derivate este cel al termenilor proveniți din interjecții, totalizând 46 de descendenți, adică 14,83\%. Dat fiind caracterul popular-dialectal al DGS, era de aşteptat ca numărul derivatelor onomatopeice să fie mult mai mare, ceea ce, însă, nu se întâmplă întrucât o mulțime dintre derivatele de acest tip atestate în graiurile sudice sunt prezente în dicționarele limbii române şi, în consecință, nu au fost reținute. Pe de altă parte, subliniem că nici în studiul Laurei Vasiliu descendenții din interjecții nu sunt prea numeroşi, ocupând doar un procent de 7\% (L. Vasiliu 1967: 119). Situația se explică, parțial, prin faptul că, la nivelul acestei categorii de elemente derivate, variantele în - $\breve{a} i$, $-\hat{a} i$ predomină 9 .

Aşadar, prezența în DGS a derivatelor verbale în -ui de origine onomatopeică se datoreşte fie preferinței pentru anumite forme, construite cu acest sufix, inexistente în dicționare: $a$ chițuí [d. iepuri] ,a scoate sunete ascuțite specifice speciei", fie pentru sensul sugestiv special al termenului creat: a imbuí [fig., d. vița de vie] ,,a da mugurii, a înmuguri”; uşui ,,a alunga o oaie cu stigătul h â ş t i” a fost reținut în dicționarul dialectal atât pentru sensul deosebit de cel cunoscut al lui hâşâi (,a alunga o pasăre”), cât şi pentru forma cu $h$ - căzut şi cu $\hat{a}>u$; zdupui

\footnotetext{
${ }^{9}$ Explicația acestei situații se află în însăşi originea interjecțiilor din respectiva categorie: majoritatea derivatelor verbale în -ui au căpătat această formă sub influența vocalei din temă: bubui < bubăi, pufuí < pufăi (cu $u-\breve{a}>u-u$ (cf. L. Vasiliu 1967: 119).
} 
„a tropăi” a fost preferat în grai datorită „,suitei” de vocale $u \ldots u$, mai sugestivă decât $\breve{a} . . . u$ din forma $z$ dupăi întâlnită în alte surse (atestată în dicționare tot ca regionalism); pufui, definit în DGS ,a tencui” prezintă acest sens special, desprins, probabil din interjecția, de asemenea, atestată în dicționare, cu sensul „cuvânt care redă zgomotul produs de lovirea în cădere a unui corp pe o suprafață moale", sens desprins de autorii dicționarului din citatul care ilustrează cuvântul respectiv: $L a$ noi, după ce le bagă-n şipcă [casele], îi dă ca să netezească pământu, îi dă... le pufuiéşte tot cu pământ aşa (GM, pct. 753), de unde se deduce că este vorba de un al doilea strat de pământ care se aplică, imediat, peste primul încă moale.

4.3. Creațiile deverbale, reprezentând derivate rezultate prin sufixarea cu -ui a unui verb simplu, nesufixat, numără 25 de unități, adică $1,19 \%$ din totalul verbelor aparținând acestei categorii.

Posibilităţile de creare a acestei subdiviziuni sunt limitate, reducându-se la adăugarea elementului derivativ $-u i$ la verbele simple, primare, nesufixate sau la simpla schimbare de sufix (cu eventuale modificări uşoare de sens): frângui < frấnge, pălui ${ }^{2} \mathbf{1}^{0}$ [d. iarbă] „a se zvânta, a se usca] < păli $\mathbf{3}^{\circ}$ refl. [d. brânză, carne etc.] ,a (se) zvânta, a (se) usca”, probui ,a încerca, a proba" < probi ,,a încerca” (< probá), tărăgui ,a vorbi mult, vrute şi nevrute” < tărăgăi ,a zăcea, a boli (timp îndelungat)", țipuí „, țipa" < țipá. Uneori, sufixul -ui se ataşează la una dintre formele flexionare ale verbului matcă: firui ,a drăcui” < fire-ai (al dracului), zăcătui $\mathbf{1}^{\mathbf{0}}$,a zăcea, a boli”; $\mathbf{2}^{\mathbf{0}}$ [fig., d. săpunul proaspăt preparat] ,, a sta fără să fie mişcat" < zăcút sau din záce + -ătuí, una dintre variantele lui -ui (cf. L. Vasiliu 1967: 135-136).

Adesea, stabilirea filiaţiei unei forme verbale în -ui este greu de hotărât, fie pentru că aceasta poate proveni din perechea nesufixată, fie direct dintr-o formă nominală ${ }^{10}$ : impilduí ,a discuta în contradictoriu; a se certa" poate proveni din perechea nesufixată, impildí , a avea discuții în contradictoriu; a se certa" sau din substantivul impilduiálă „discuție în contradictoriu, ceartă”.

Alteori, precizarea originii unui termen este cu atât mai dificilă, cu cât soluțiile propuse sunt contradictorii: leşuí „a leşina”, întâlnit în DGS cu o mulțime de atestări din Oltenia (localități din Vâlcea, Dolj, Olt) şi în Muntenia (județele Argeş, Olt), cu o familie de termeni bogată: leşuială „stare de leşin”, leşuít „leşinat (de foame)" şi cu etimonul stabilit de către DA, după părerea noastră, clar, în cuvântul leş, „greutate la inimă, leşin”, atestat în DDRF şi, apoi, în Pamfile, B., 42), a continuat să suscite discuții şi să provoace semne de întrebare referitor la etimologie $^{11}$.

\footnotetext{
${ }^{10}$ O situație similară este exemplificată de L. Vasiliu (1967: 118): căpăstruí < căpăstrá sau căpăstrui $<$ căpắstru.

${ }^{11}$ L. Vasiliu 1967: 119, citându-l pe Alf Lombard 1955, îşi pune întrebarea cum s-a putut trece de la sufixul -ina (din leşina) la -ui (din leşui); autoarea se miră de propunerea lui Alf Lombard de a-1 considera, eventual, pe leşui un împrumut din magh. lesni, sugestie formulată, de altfel, şi în DA, aşa după cum ea însăşi se întreabă dacă n-ar putea să fie un derivat de la leşie.
} 
5. O chestiune discutată în general sau cu referire la o anumită categorie dintre derivatele în - $u i$ (nominale, onomatopeice, deverbale) sau cu privire la unele dintre variantele sufixului -ui precedat de -l- (-ăluí, -eluí, -iluí, -ului) are în vedere conţinutul semantic al sufixului.

5.1. Se consideră, pe de o parte, că, atunci când formează derivate de la temele nominale şi de la interjecții, sufixul are valoare semantică (L. Vasiliu 1967: 123). Urmărind cu atenție materialul din DGS, dar şi exemplele şi întreaga discuție din articolul citat, se pare că afirmația nu se susține în totalitate, ci doar, eventual, în anumite puncte şi numai în unele cazuri. Din exemplele discutate deja pentru cele trei categorii de verbe derivate cu -ui se pot constata următoarele situații.

5.1.1. Atunci când derivarea se referă la nume şi la interjecții, acțiunea, starea etc. exprimate de verbul rezultat prin sufixare se desfăşoară sau are loc în legătură cu obiectul sau elementul exprimat prin tema cuvântului supus derivării, care poate fi intermediar, agent, obiect propriu-zis, rezultat, respectiv, poate fi nume de acțiune sau de ocupație, nume de obiecte concrete, adjective, interjecții, deci se poate spune că -ui are doar rolul de a conferi sens, valoare verbală numelui ori interjecției: cárne > cărnui $\mathbf{1}^{\mathbf{0}}$,a curăța de carne pieile înainte de tăbăcit”; $\mathbf{2}^{\mathbf{0}}$,,a scoate, a desface carnea de pe oasele mari (la sacrificarea unui animal)", grésie $>$ gresuí „a ascuți coasa cu gresia”, hop/hup > hupuí „,a sălta oamenii pe brațe în cadrul obiceiurilor de Sfântul Ion, strigând hop, hop”, țutțu „leagăn” > țuțuí ,a legăna copilul mic dându-l în ț u ț u". Aşadar, sensul propriu-zis al derivatului nu este conferit de sufixul în sine, ci de elementul de la care derivă acest termen, sufixul are doar rolul morfologic de a transforma numele sau interjecția în verb.

5.1.2. Nici în cazul derivatelor deverbale „sufixul nu are un conținut semantic distinct" (L. Vasiliu 1967: 123).

Aşa cum reiese din cele prezentate mai sus (sub 4.5.), inclusiv din exemplele citate, eventualele modificări intervenite prin trecerea de la un verb la altul se rezumă la schimbarea conjugării, deci, se poate spune că este vorba, şi de această dată, de o modificare doar în plan m o r folog i c: frấnge (conjug. a III-a, cu sensul cunoscut) > frânguí (conjug. a IV-a), glosat „a frânge, a rupe”, țipá (conjug. I) , a striga cu glas tare şi ascuțit” > țipuí (conjug. a IV-a) ,a țipa”.

6. Un alt punct de vedere prin care pot fi clasificate verbele în -ui, -ălui (-eluí, -iluí, -ului etc.) este cel al originii elementelor (verbelor) rezultate prin sufixare.

6.1. Cele trei grupuri discutate deja (nominale, onomatopeice, deverbale), reprezentând 265 de termeni (adică 85, 48\%) sunt toate formate pe terenul limbii române de la cuvinte româneşti.

6.2. Un grup relativ restrâns (comparativ cu cel al formațiilor româneşti), respectiv 43 de elemente $(13,87 \%)$, este constituit din cuvinte imprumutate ca atare, în diverse perioade ale evoluției limbii române, (şi adaptate sistemului acesteia) din limbile maghiară, slavă veche sau din diferite limbi slave, din germană etc., având, de multe ori, sensuri care nu se suprapun decât parțial cu sensul originar. 
6.2.1. Cele mai numeroase sunt elementele de origine $\mathrm{magh}$ i a $\breve{a}$, numărând 18 cuvinte $(41,86 \%)$, dintre care amintim doar câteva: bănuí $(<$ magh. bán) $\mathbf{1}^{\mathbf{0}}$,a socoti, a evalua, a aprecia”; $\mathbf{2}^{\mathbf{0}}$,a nu fi sigur, a se îndoi”; $\mathbf{3}^{\mathbf{0}}$, a avea înclinație, atracție (spre ceva); $\mathbf{4}^{\mathbf{0}}$, a tinde să se răstoarne; a se înclina”, bizui (< magh. bizni) $\mathbf{1}^{\mathbf{0}}$ „,a învinge, a birui”; $\mathbf{2}^{\mathbf{0}}$ refl. ,a fi sigur de ceva; a avea siguranță”, mântuí (< magh. ment) ,a se termina”, mistuí ( < magh. emészt) $\mathbf{1}^{\mathbf{0}}$ "a mesteca mâncarea în gură"; $\mathbf{2}^{\mathbf{0}}$ refl. ,a se dizolva”; $\mathbf{3}^{\mathbf{0}}$,, a fi acoperit total, a nu se mai vedea”, răgădui (< magh. ragad) ,a boli; a rămâne suferind” ş. a.

6.2.2. Al doilea grup (considerat din punct de vedere numeric) - 9 cuvinte, adică $20,93 \%$ ) este format din elementele provenite din slavă veche, bulgară, ucraineană, sârbă: întencuí $<$ în + tencuí $\left(<\right.$ ucr. tyn kuvaty), jupuí $\left(<\right.$ bg. župia) $\mathbf{1}^{\circ}$ „a curăța, a desface pănuşile de pe ştiulete”; $\mathbf{2}^{\circ}$,a curăța penele de pe o pasăre; a jumuli”, pecetlui (slv. pečatīlěti) [d. albine] ,a acoperi cu ceară alveolele fagurilor”, strădui (< slv. stradati) ,a necăji, a chinui, a tortura”, zvidui ( $<$ ucr. izvidati) ,a (se) vindeca, a (se) însănătoşi”".

6.2.3. Alte împrumuturi (latine târzii, germane etc.) sunt reprezentate doar prin unu-două cuvinte, ca, de exemplu, abțiguí (probabil germ. abziehen, prin apropiere de Abzug, v. DELR, I, s.v.) refl. ,a se ameți de băutură; a se chercheli”, rictui (< germ. richten) ,a curăța buştenii de crengi”.

6.3. Pe lângă împrumuturile sigure, în DGS se întâlnesc şi situaţii pentru care etimologiile propuse, sugerate sau presupuse nu pot fi acceptate.

Verbul cinui este întrebuințat în dicționarul nostru în formă activă, tranzitivă „a spăla, a îngriji”: Nu-şi cinuie corpu, e murdar şi reflexivă „a se spăla” este preluat din ALRR-Munt. şi Dobr., I, h. 215, pct. 816 - Mereni, comuna Conțeşti, Db). În DA, cuvântul apare s.v. ciná, ca variantă de conjugarea a IV-a, ipostază în care este discutat şi de L. Vasiliu 1967: 120.

Cuvântul cinuí din DGS este clar că semantic nu poate fi înrudit cu ciná, ci, de fapt, reprezintă o variantă formală simplificată a lui cinătui (neatestat în dicţionarul graiurilor sudice), întâlnit în DA s.v., semnificând ,a curăţa de pene şi de puf, a jumuli o pasăre; a pregăti pentru pus la foc o pasăre sau un peşte", atestat în diverse surse, dar şi în TDRG, cu semnalări din Moldova, Bucovina şi Maramureş (v. DA, s.v.). Cuvântul reprezintă un derivat cu sufixul -ui din magh. csinált, participiul verbului csinálni ,a face, a pregăti”.

6.4. Pentru câteva dintre verbele construite cu sufixul -ui (inexistente în dicționare) nu am reuşit să aflăm/să identificăm etimonul. Astfel, alibzuí refl. [d. scânduri] ,a se îmbina”: Se bate cu maiu [pământul, pe partea de jos a camerei] s̆a se alibzuie, să se netezească, să se apropie două blăni (exemplu preluat din NALR-Olt., pct. 905 - Gorj), întâlnit, în acelaşi punct (905) din Gorj, sub forma de participiu alizguit, cu un sens diferit, ,netezit bine, dat la rindea” (atestare neluată în seamă de către cercetătorii care au fişat materialul pentru DGS şi, în consecință, neinclus în lucrare) nu mai este atestat în alte izvoare. 
7. Discuțiile şi observațiile asupra materialului lexical din DGS s-ar putea continua cu o mulțime de alte caracteristici privind bogăția şi varietatea acestuia, cu valoarea și implicatiile semantice dezvoltate prin folosirea sufixului verbal -ui, dar şi în legătură cu prezența unor categorii de elemente compuse ale sufixului: -ălui, -elui, -ilui, -olui, -ului, -ătui, -ăzui etc. etc. (cf. L. Vasiliu, 1967: 126-138), formații folosite în diverse variante condiționate de originea termenilor (împrumutați) sau de contextul fonetic în care sunt utilizate.

Toate acestea, precum şi o serie de reveniri asupra unor termeni neelucidaţi din punct de vedere etimologic ne obligă să continuăm, într-o altă intervenție, discuțiile în legătură cu sufixul -ui aşa cum este întâlnit în materialul lexical din DGS.

\section{BIBLIOGRAFIE}

ALRR-Munt. Dobr., I = Atlasul lingvistic român pe regiuni. Muntenia şi Dobrogea, de Teofil Teaha, Mihai Conțiu, Ion Ionică, Paul Lăzărescu, Bogdan Marinescu, Nicolae Saramandu, Magdalena Vulpe, vol. I, Bucureşti, Editura Academiei Române, 1996.

Brâncuş 2008 [1976] = Gr. Brâncuş, Productivitatea conjugărilor în româna actuală, în „Studii şi cercetări lingvistice”, XXVII, 5, p. 485-492, republicat în Gr. Brâncuş, Studii de istorie a limbii române, II, Bucureşti, Editura Academiei Române, p. 11-17.

DA = Academia Română, Dicționarul limbii române, Bucureşti, 1913-1948.

DDRF $\quad=$ Frederic Damé, Nouveau Dictionnaire roumain-français, vol. I-IV, Bucarest, 1893-1895.

DELR, I = Dicționarul etimologic al limbii române. Volumul I, $A-B$, Editura Academiei Române, Bucureşti, 2011.

Densusianu, HLR, II = Ovid Densusianu, Histoire de la langue Roumaine, Tome II. Le seizième siècle, Paris, Librairie Ernest Letoux, 1938.

DEX 1975 = Academia Română, Institutul de Lingvistică „Iorgu Iordan”, DEX. Dicționarul explicativ al limbii române, ediția I, Bucureşti.

DEX

= Academia Română, Institutul de Lingvistică „Iorgu Iordan”, DEX. Dicționarul explicativ al limbii române, ediția a II-a, Bucureşti, 1996.

DGS = Dicționarul graiurilor dacoromâne sudice, de Ion Ionică, Maria Marin, Anca Marinescu, Iulia Mărgărit, Teofil Teaha. Coordonator: Maria Marin, Bucureşti, Editura Academiei Române, vol. I (literele $A-C$ ), 2009; vol. II (literele $D-O$ ), 2010; vol. III (literele $P-Z$ ), 2011.

DLR = Academia Română, Dicționarul limbii române (DLR). Serie nouă, Bucureşti, 1965-2010.

Faiciuc 1983 = Ion Faiciuc, Derivate cu sufixul diminutival -uc în Maramureş, în „Cercetări de lingvistică", 17, 1, p. 99-109.

GALR = Gramatica limbii române. I. Cuvântul, Bucureşti, Editura Academiei Române, 2005.

GM

= Glosar dialectal. Muntenia, de Maria Marin, Iulia Mărgărit, Bucureşti, Editura Academiei Române, 1999.

Ionică 1984

Iordan 1936

= Ion Ionică, Subdialectul muntean, în Tratat, p. 163-208.

= Iorgu Iordan, Compuse româneşti cu în-, în „Buletinul Institutului de Filologie Română «Alexandru Philippide», III, p. 57-117.

Lexic reg. $\quad$ = Lexic regional, I, redactor coordonator: Gh. Bulgăr, 1960.

Lombard $1955=$ Alf Lombard, Le verbe roumain, vol. II, Étude morphologique, II, Lund, 1955. 
Marin 2019 = Maria Marin, Despre unele particularități ale utilizării formelor de conjugare în graiurile dacoromâne sudice, în Omagiu profesorului Grigore Brâncuş la 90 de ani, Editori: Gh. Chivu, Cătălina Vătăşescu, Editura Universităţii din Bucureşti, p. 269-273.

Mărgărit 2009 = Iulia Mărgărit, Vocabularul graiurilor munteneş̧ti actuale, Bucureşti, Editura Academiei Române.

NALR-Olt.

= Noul atlas lingvistic român pe regiuni. Oltenia, întocmit sub conducerea lui Boris Cazacu, de Teofil Teaha, Ion Ionică şi Valeriu Rusu, vol. I-V, Bucureşti, Editura Academiei, 1967-1984.

Pamfile, B. $\quad$ = Tudor Pamfile, Boli şi leacuri la oameni, vite şi păsări după datinile şi credințele poporului român, adunate din comuna Țepu (Tecuciu) de..., Bucureşti, 1911.

Petrovici 1948 = E. Petrovici, Sufixul -ui al verbelor de origine maghiară, în „Dacoromania”, XI, p. 188-190.

Pușcariu 1929-1930 = Sextil Puşcariu, Pe marginea cărților, în „Dacoromania”, VI, 1929-1930 p. $520-521$.

Radu 2017 = Carmen-Ioana Radu, Sistemul diminutivelor în graiul sălăjean, în TD-Sălaj, p. $58-64$.

Rosetti $1950=$ Al. Rosetti, Imprumuturi maghiare prin intermediul slav, în „Studii şi cercetări lingvistice", I, p. 88-90.

Skok 1929 = P. Skok, Des rapports linguistiques slavo-roumains, în „Slavia” VIII (1929), p. 776-790.

TDRG

TD-Sălaj

= H. Tiktin, Rumänisch-deutsches Wörterbuch, Bucureşti, 1895-1925.

= Maria Marin (coord.), Mihai Conțiu, Bogdan Marinescu, Carmen-Ioana Radu, Marilena Tiugan, Graiurile din Sălaj, Bucureşti, Editura Academiei Române, 2017.

Tratat

= Tratat de dialectologie românească. Coordonator Valeriu Rusu, Craiova, Editura Scrisul Românesc, 1984.

L. Vasiliu 1967 = Laura Vasiliu, Sufixul verbal -ui şi compusele lui, în Studii şi materiale privitoare la formarea cuvintelor în limba română, vol. al IV-lea, Bucureşti, Editura Academiei Române, 1967, p. 113-142.

Vulpe 1984

= Magdalena Vulpe, Subdialectul maramureşean, în Tratat, p. 320-354.

\title{
ABOUT THE - $u i$ VERBAL SUFFIX IN DACO-ROMANIAN SOUTH SUBDIALECTS
}

\begin{abstract}
The article tries to describe the usage of the $-u i$ verbal suffix in the dialectal variant from Oltenia (Lesser Wallachia), Muntenia (Greater Wallachia) and Dobruja as reflected in Dicționarul graiurilor dacoromâne sudice (Dictionary of Daco-Romanian South Subdialects) (DGS).

After a short presentation of the history of this derivative element, we discuss and explain different specific situations that were encountered in the gathered material; this, we can show its richness, variety and importance for revealing some new aspects of dialectal variants, in general, and of south subdialects, in particular.
\end{abstract}

Institutul de Lingvistică al Academiei Române „Iorgu Iordan - Alexandru Rosetti” Bucureşti, Calea 13 Septembrie nr. 13 